\title{
Are Replication Studies Infrequent Because of Negative Attitudes? Insights From a Survey of Attitudes and Practices in Second Language Research
}

Kevin McManus, Penn State University, USA, kmcmanus@psu.edu

\begin{abstract}
Replication is a research methodology designed to verify, consolidate, and generalize knowledge and understanding within empirical fields of study. In second language studies, however, reviews share widespread concern about the infrequency of replication. A common but speculative explanation for this situation is that replication studies are not valued because they lack originality and/or innovation. To better understand and respond to the infrequency of replication in our field, 354 researchers were surveyed about their attitudes toward replication and their practices conducting replication studies. Responses included world-wide participation from researchers with and without replication experience. Overall, replications were evaluated as relevant and valuable to the field. Claims that replication studies lack originality/innovation were not supported. However, dissemination issues were identified: half of published replication studies lacked explicit labeling and one quarter of completed replications were unpublished. Explicit labeling of replication studies and training in research methodology and dissemination can address this situation.
\end{abstract}




\section{Are Replication Studies Infrequent Because of Negative Attitudes? Insights from a Survey of Attitudes and Practices in Second Language Research}

Study quality and methodological rigor, including how research data are collected, analyzed, and interpreted, are now a major focus of attention in the field of second language (L2) studies (Gass et al., 2021; Plonsky, 2013). This “methodological turn” (Byrnes, 2013) has been fundamental to the growth and credibility of the discipline because theories about L2 learning are built and developed by collecting, analyzing, and interpreting data. However, a critical problem facing empirical disciplines like L2 studies is that established findings and previous studies appear to be seldom revisited (Marsden et al., 2018; Zwaan et al., 2018). This means that new studies, theories, and applications regularly build on unverified, unconfirmed, and sometimes scanty results.

As reviews of the field have repeatedly noted, replication studies are critically needed to consolidate and strengthen the field's evidence base (Marsden et al., 2018; Porte, 2012). This is because replication allows us to better understand how a study's research data were collected, measured, and analyzed, as well as the extent to which unexpected and/or unanticipated factors potentially influenced the results (Porte \& McManus, 2019; Schmidt, 2009). Replication is therefore one way to assure the quality of our work. In L2 research, however, revisiting a study to understand the nature, validity, and reliability of its findings is still not yet considered an accepted or necessary part of the research process.

One explanation for infrequent amounts of replication in the field is that replication studies are not valued because they lack originality and/or innovation (Marsden et al., 2018; Porte, 2012). For example, Porte and Richards (2012) surmised that replication "is regarded as low-prestige, mundane, 'unoriginal', or 'non-academic' and therefore not encouraged by faculty" 
(p. 285, see also Marsden et al., 2018; Porte \& McManus, 2019). Small-scale surveys from neighboring disciplines provide some support for these claims. In translation and interpreting studies, for example, Olalla-Soler's (2020) survey of 52 researchers indicated that approximately $25 \%$ of respondents saw replication as "uninteresting" and "not a priority", despite views that replication is needed to grow the discipline. In a survey of 73 researchers in computer science education (Ahadi et al., 2016), respondents agreed that "original studies are more prestigious than replication studies" (p. 7) and thought that replications contributed little toward citation and grant success. These attitudes were reinforced by Easley et al.'s (2013) survey of journal editors: " social science editors $[n=31]$ think of replication as an uncreative process that unfairly displaces 'original' and important studies” (p. 1459). Slightly more optimistic attitudes were reported by $\mathrm{Mu}$ and Matsuda (2016) in a survey of 107 authors in the Journal of Second Language Writing, however. Close to half of respondents agreed that "replication studies count towards hiring, tenure, and promotion decisions as much as original studies do" (p. 207), but this question was ignored by $40 \%$ of respondents. Respondents additionally evaluated replication studies as "too risky" and "potentially injurious" to tenure and/or promotion (p. 208).

Taken together, even though a small body of research suggests that replication is needed, the perceived relevance and value of conducting replication studies is unclear. As a result, negative or ambivalent attitudes toward the relevance, value, and originality/innovation of replication studies could explain their infrequency. It is also possible that attitudes toward replication might be moderated by researcher experience and training (e.g., career stage, research methodology courses taken, years since receiving a $\mathrm{PhD}$ ), in line with findings recently reported by Isbell et al. (under review) and Loewen et al. (2020) for research ethics and statistical knowledge. Apart from a few small-scale surveys, however, very little is known about 
researchers' attitudes toward replication and their practices conducting replication studies. To address concerns about the infrequency of replication in the field, research is needed that investigates (i) researchers' attitudes toward replication, (ii) how replication studies are reported and disseminated, and (iii) potential relationships between attitudes and researcher experience and training.

\section{Current study}

This study addressed the aforementioned gaps by investigating researchers' attitudes toward replication and the practices of researchers who have carried out replications in L2 studies. One particular motivation for this investigation is that discourse around study quality, replication, and a perceived crisis in the reproducibility of empirical results has increased within recent years (e.g., Gass \& Plonsky, 2020; Marsden et al., 2018). One example of this is Marsden et al.'s (2018) narrative and systematic review that refocused attention on the lack of replication in the field (see also Language Teaching Review Panel, 2008; Porte, 2012). Based on a sample of 67 self-identified replication studies, Marsden et al. estimated a mean rate of 1 published replication for every 400 articles. The review concluded with sixteen recommendations to support future replication research, including ways to address publication bias, labeling ambiguities, and promote greater openness and transparency in research. The field has also witnessed a variety of initiatives designed to support and promote replication, including the creation of replication studies as specific manuscript types in some journals (e.g., Language Teaching, Studies in Second Language Acquisition), funding mechanisms to support replication of influential studies (e.g., Institute of Education Sciences), explicit guidelines from professional societies articulating the value and place of replication studies in decisions about tenure and 
promotion (e.g., American Association for Applied Linguistics), as well a recent textbook that guides researchers through the replication research process (Porte \& McManus, 2019). Together, these are important initiatives that may have influenced attitudes toward replication.

In the current study, three related questions were investigated to better understand why replication studies appear infrequent in L2 studies. First, researchers were surveyed about their attitudes toward replication. This question responds to claims that replication studies are infrequent because they are not relevant and/or are not valuable to the field. Second, researchers with replication experience were surveyed about their practices conducting and reporting replication studies. This question seeks to understand in what ways claims about the infrequency of replication studies might be explained by factors related to how replications are reported and disseminated. Third, relationships between researcher background characteristics and attitudes toward replication were examined to understand in what ways experience in the field, including career stage, rate of publication, and research methods training, potentially shapes attitudes toward replication. The following research questions were investigated:

RQ1. What are the attitudes of researchers toward replication?

RQ2. What are the practices of researchers who have carried out replication studies?

RQ3. In what ways do researcher background variables relate to attitudes toward replication?

\section{Method}

\section{Participants}

The target population was researchers, including PhD students, in the field of L2 studies. Data were collected between September 2020 and March 2021. Following Isbell et al. (under 
review) and Loewen et al. (2020), two techniques were used to obtain a broad and large sample of the target population. First, names and emails were extracted from recent conference programs connected with L2 research: International Association of Applied Linguistics (2017), the L2 acquisition, language acquisition, and attrition strand of the American Association of Applied Linguistics (2017 - 2020), British Association for Applied Linguistics (2017 - 2019), European Second Language Association (2018, 2019), Japan Second Language Association (2017 - 2019), and Second Language Research Forum (2017 - 2019). Internet searches using google.com were conducted to collect missing email addresses. Using this procedure, 3285 unique contacts were sent and received an invitation to the survey. Second, survey links were posted to the International Symposium on Bilingualism and Info-CHILDES listservs, social media (Twitter and the Applied Linguistics Research Methods Facebook Group), and the Linguist List. Researchers were also invited to share the link with colleagues in L2 studies.

Using these recruitment methods, 556 people started the survey by clicking on the survey link and 354 completed the survey (i.e., provided a response for all questions). The final sample included 354 respondents from 45 different countries (44\% in North America, 29\% in Europe, $10 \%$ in Asia, 6\% in South America, 2\% in each of Africa and Australia; "no response" = 7\%). In terms of career stage, $24 \%$ of respondents self-identified as $\mathrm{PhD}$ students, $8 \%$ as postdoctoral researchers, $25 \%$ as assistant professors, $19 \%$ as associate professors, and $16 \%$ as full professors ("other" $=1 \%$, "no response" $=7 \%$ ). Additional characteristics of the data sample with information about years since receiving the $\mathrm{PhD}$, publishing experience, research orientation, and research training are summarized in Table 1. 


\section{Table 1.}

Characteristics of the data sample

\begin{tabular}{lcccccccc}
\hline & $N$ & Mean & SD & $\begin{array}{c}\text { 95\% CIs } \\
\text { LL, UL }\end{array}$ & Median & IQR & $\begin{array}{c}\text { Minimum } \\
\text { value }\end{array}$ & $\begin{array}{c}\text { Maximum } \\
\text { value }\end{array}$ \\
\hline $\begin{array}{l}\text { Years since receiving PhD } \\
\text { Mean number of journal articles }\end{array}$ & 310 & 7.6 & 9 & $6.6,8.6$ & 5 & 11.8 & 0 & 47 \\
published / year & 1.7 & 1.2 & $1.6,1.8$ & 1 & 1 & 0 & 5 \\
$\begin{array}{l}\text { Research orientation } \\
\text { Research methods courses taken }\end{array}$ & 330 & 2.4 & 1 & $2.3,2.5$ & 2 & 1 & 1 & 5 \\
\hline
\end{tabular}

Note. Research orientation was coded as follows: $1=$ quantitative only, $2=$ mostly quantitative, $3=$ equal parts quantitative and qualitative, $4=$ mostly qualitative, $5=$ all qualitative.

\section{Survey}

The survey's design was informed by previous work investigating researchers' attitudes toward replication and their practices conducting replication studies (Ahadi et al., 2016; Mu \& Matsuda, 2016; Olalla-Soler, 2020). In order to increase comparability between the current study and recent research on this topic, a modified version of Olalla-Soler's (2020) survey was used. Pilot testing with twelve researchers in L2 studies resulted in revisions to the survey's flow, labeling, questions, and response options. The survey is available in the online supplementary materials and from OSF, https://osf.io/6kfxz (see also IRIS).

The survey included three sections: section 1: attitudes toward replication; section 2: replication practices; and section 3: background information. Before beginning the survey, respondents were provided with a concise definition of a replication study ("A replication study is defined as an empirical study that involves repeating the research procedure of a previous piece of work, with or without changes (Schmidt 2009)") and a definition of L2 research ("L2 research includes any research that involves analyzing data from L2 speakers"). The survey was designed and administered using Qualtrics software (2021). The "survey flow" option in 
Qualtrics customized the order of the questions depending on answers. Therefore, no respondent was asked about replication practices if they had not conducted a replication study.

In section 1, respondents were asked about their attitudes toward conducting replication research in the field of L2 studies (e.g., "Do you think researchers should replicate their own studies, those of other researchers, or both?", "Do you think the amount of replication in L2 research should remain the same, increase, or decrease?"). In section 2, respondents who indicated that they had replicated one or more studies were asked about their experiences and practices carrying out, reporting, and publishing their replication(s) (e.g., "How many of your replications were exact/direct, close/partial, or conceptual" [definitions of each type were provided], "How many of your replications have been explicitly labeled as a replication in the title or abstract of the publication?"). In section 3, background information was requested, including country of residence, year $\mathrm{PhD}$ was received, current position, publishing experience, and research orientation.

\section{Analyses}

Only data from completed surveys were used in the analysis, determined as a respondent providing a response for all questions, including "no response" (Data are available from OSF, https://osf.io/6kfxz). An estimation approach to data analysis was used (Cumming \& CalinJageman, 2017), in which analyses primarily involved descriptive statistics for each survey question (mean, standard deviation, 95\% confidence intervals (CIs), median, interquartile range). CIs with short intervals that do not cross zero are interpreted as indicators of a statistically meaningful effect. In addition, CIs can be used to generalize beyond a specific sample and make predictions for future replication studies (see Cumming \& Calin-Jageman, 2017). 
To address RQ3 about potential relationships between attitudes toward replication and researcher experience/background, Spearman-Rank correlations by bootstrapping (with 1000 replicates and 95\% CIs) were performed using RVAideMemoire (Hervé, 2021) in $R$ (R Core Team, 2021). The attitude data came from question 1.4 in the survey and the background variables were career stage, years since $\mathrm{PhD}$, publication rate, and statistics courses taken. All instances of "no response" were coded as NA. Estimates of effect were interpreted using correlation coefficients and their $95 \%$ confidence intervals (CIs). Correlation coefficients around 0.25, 0.40, 0.60 are interpreted as small, medium, large, respectively (Plonsky \& Oswald, 2014).

\section{Results}

Results are presented as follows: Attitudes toward replication (RQ1), practices conducting replication studies (RQ2), relationships between attitudes toward replication and researcher experience/background characteristics (RQ3). Results reported for specific survey questions are cross-referenced to the supplementary materials.

\section{What are the attitudes of researchers toward replication?}

Overall, respondents expressed very positive attitudes toward the place and value of replication in the field (Q1.4; see Table 2 and Figure 1). Using a scale from 100 (strongly agree) to 0 (strongly disagree), respondents strongly agreed that replications "are valuable to the field", "strengthen a discipline", and "are relevant to L2 research". Respondents also expressed considerable agreement with claims that replications can "consolidate", "expand", and "verify" previous results. In addition, respondents disagreed with claims that replications lack "innovation" and "originality". Some statements elicited relatively ambivalent ratings, however, 
including that replications "are negatively evaluated by reviewers" and "question the original researcher and their findings".

The histograms in Figure 1, which show counts of individual responses (in bins of ten), both reinforce these measures of central tendency and provide more nuance. For example, statements about the relevance and value of replication show counts that are very heavily skewed toward the "strongly agree" side of the scale. However, even though counts for statements about replications lacking in "originality" and "innovation" tend to collect toward the "strongly disagree" side of the scale, greater dispersion across the full scale is also visible. Taken together, these results suggest positive attitudes toward replication in our field, especially with regard to its relevance and value. In addition, respondents tend to disagree with claims that replications lack innovation and originality. 
Table 2.

Descriptive results for statements about replication research ranked by mean rating

\begin{tabular}{|c|c|c|c|c|c|c|}
\hline & $N$ & Mean & $\mathrm{SD}$ & $95 \% \mathrm{CI}$ & Median & IQR \\
\hline \multicolumn{7}{|l|}{ Statements rated 'strongly agree' to 'agree' } \\
\hline Replications are valuable to the field & 344 & 86.8 & 19.9 & $84.7,88.9$ & 99 & 20 \\
\hline Replications are relevant to $\mathrm{L} 2$ research & 344 & 86.2 & 20.7 & $84.1,88.4$ & 96.5 & 20 \\
\hline Replications strengthen a discipline & 345 & 85.9 & 21.5 & $83.6,88.2$ & 99 & 20 \\
\hline Replications consolidate previous results & 344 & 80.5 & 21.4 & $78.2,82.7$ & 84.5 & 30 \\
\hline Replications establish knowledge & 347 & 79.6 & 22.2 & $77.3,82.0$ & 83 & 30 \\
\hline Replications verify previous results & 343 & 77.0 & 23.3 & $74.5,79.4$ & 81 & 36.5 \\
\hline Replications expand previous results & 340 & 76.8 & 23.8 & $74.3,79.4$ & 81.5 & 31.3 \\
\hline Replications are used to learn about research methods & 338 & 74.4 & 24.7 & $71.8,77.1$ & 79 & 40 \\
\hline Replications generalize previous results & 332 & 66.3 & 28.8 & $63.2,69.4$ & 72.5 & 40 \\
\hline \multicolumn{7}{|l|}{ Statements rated 'neutral' } \\
\hline Replications are negatively evaluated by reviewers & 310 & 49.0 & 25.8 & $46.1,51.9$ & 50 & 39 \\
\hline Replications build academic reputations & 333 & 48.6 & 26.3 & $45.7,51.4$ & 50 & 40 \\
\hline $\begin{array}{l}\text { Replications question the original researcher and their } \\
\text { findinos }\end{array}$ & 341 & 443 & 308 & 410476 & 50 & 53 \\
\hline Replications are not a priority in L2 research right now & 337 & 43.6 & 32.9 & $40.1,47.1$ & 48 & 61 \\
\hline \multicolumn{7}{|l|}{ Statements rated 'disagree' to 'strongly disagree' } \\
\hline Replications lack originality & 340 & 37.9 & 30.3 & $34.7,41.1$ & 34 & 50 \\
\hline Replications lack innovation & 336 & 34.9 & 28.6 & $31.8,38.0$ & 30 & 44.5 \\
\hline
\end{tabular}

Note. Respondents rated each item on a scale of 0 ('strongly disagree') to100 ('strongly agree') 


\section{Figure 1.}

Histograms showing respondents' ratings of statements about replication research

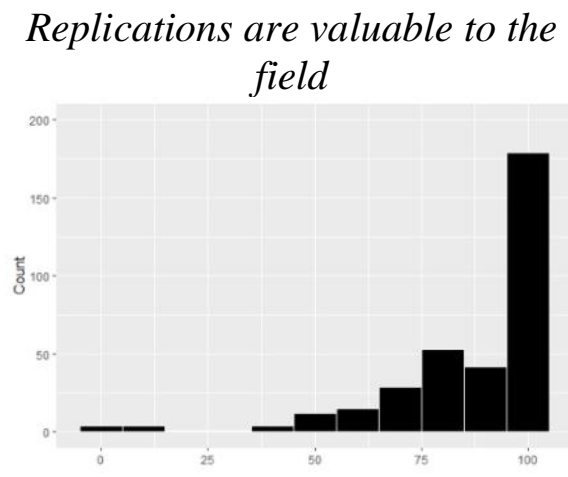

Replications establish knowledge

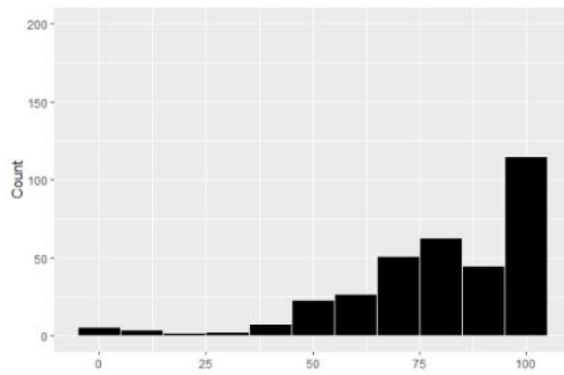

Replications are relevant to $L 2$ research

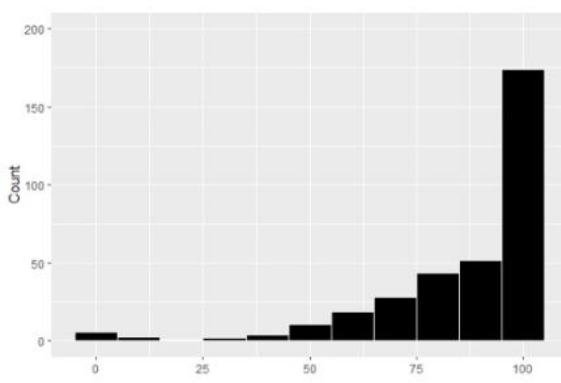

Replications expand previous results

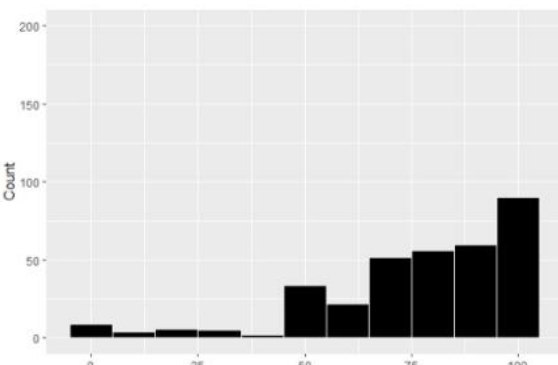

Replications strengthen a discipline

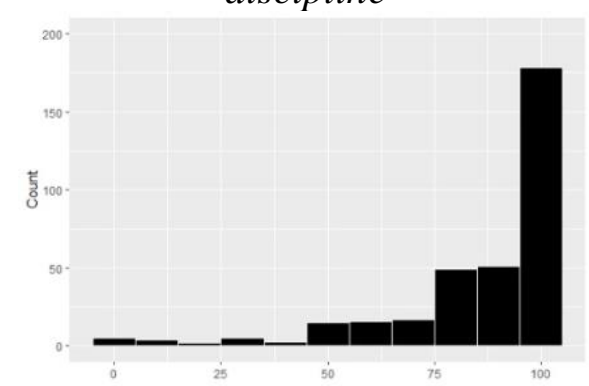

Replications verify previous results

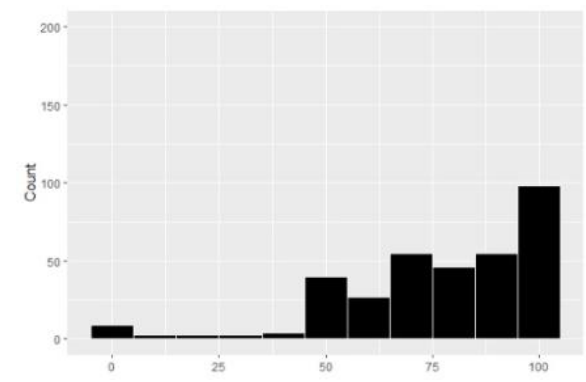

Replications consolidate previous results

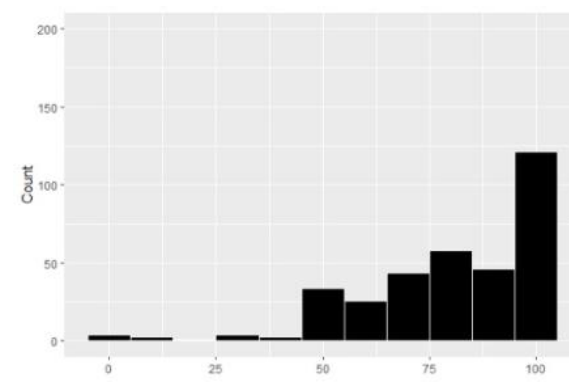

Replications are used to learn about research methods

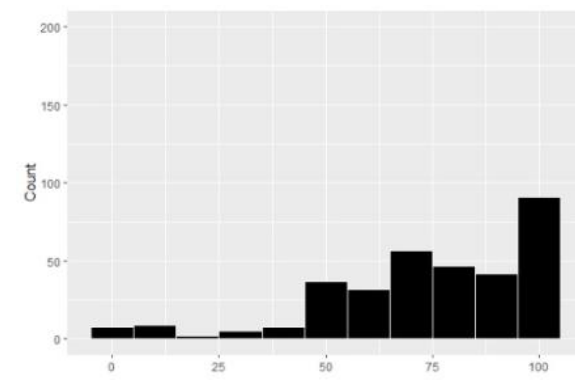


Replications generalize previous results

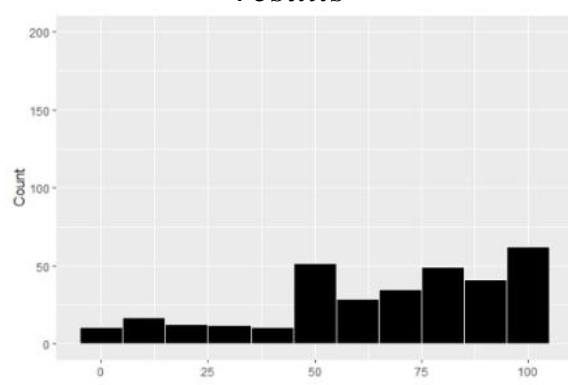

Replications are negatively evaluated by reviewers

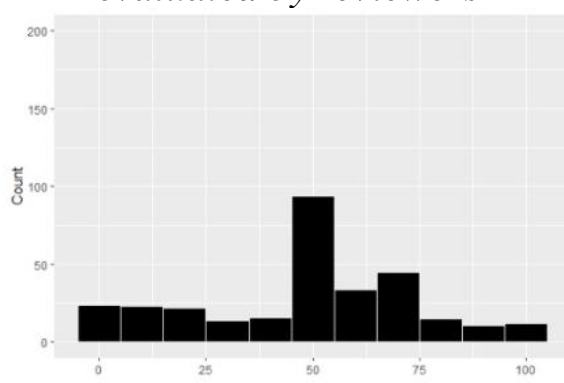

Replications question the original researcher and their findings

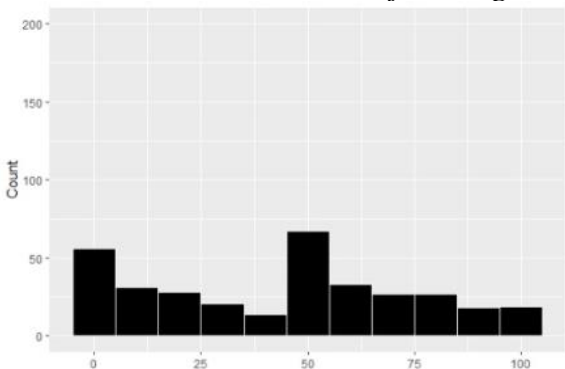

Replications lack originality

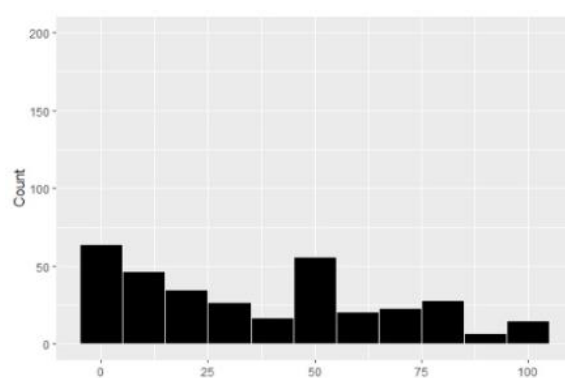

Replications are not a priority in L2 research right now

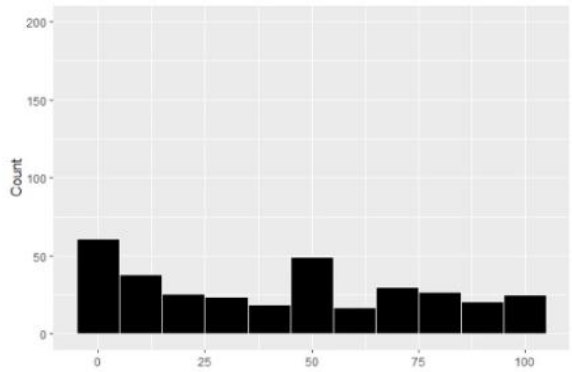

Replications lack innovation

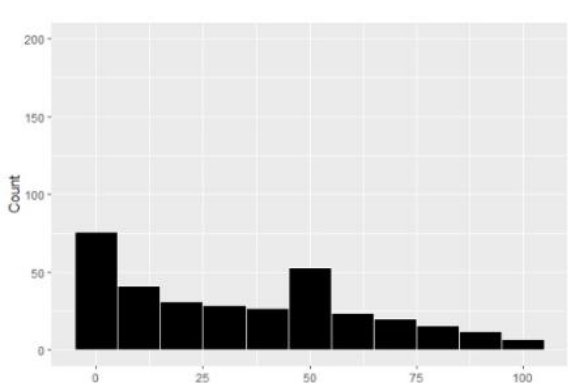

Replications build academic reputations

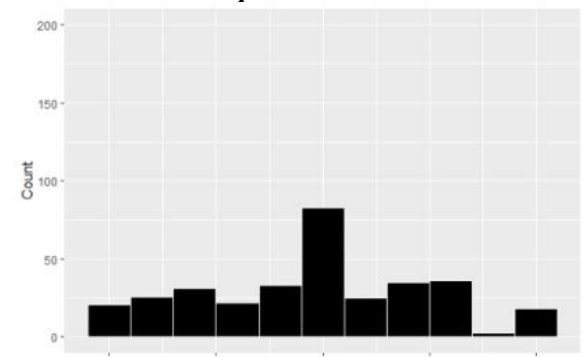

Note. Each statement was rated on a scale from 0 ('strongly disagree') to 100 ('strongly agree') 
To understand attitudes toward replication more fully, respondents were asked whether they would recommend others to replicate studies and whether they thought the amount and type of replication should change.

First, $89.3 \%(n=316)$ of 354 respondents indicated that they would recommend other researchers to carry out replication studies (Q1.1). Only 5.4\% (n=19) would not ("no response" = $5.4 \%, n=19)$. When asked which studies should be replicated (Q1.3), most respondents thought that researchers should replicate both their own studies and those of other people $(81.9 \%$, $n=290$ ). A small number of respondents thought that researchers should either replicate studies of other people only $(9.9 \%, n=35)$ or their own studies only $(3.1 \%, n=11)$. Very few respondents thought that researchers should not conduct replications $(2.5 \%, n=9$; "no response" $=2.5 \%$, $n=9)$.

Second, respondents were asked if they would support a graduate student who wanted to conduct a replication as part of their PhD project (Q1.2). Most respondents indicated that they would support this: fully support $(33.9 \%, n=120)$, support but an additional study is required (28.8\%, $n=102)$, support but with reservations $(13 \%, n=46)$. A minority of respondents selected "No, I don't think replication is appropriate for a $\mathrm{PhD}$ project" $(8.8 \%, n=31$; "maybe" $=4.8 \%$, $n=17$; "no response" $=5.4 \%, n=19$ ). Some respondents added that it would depend on the quality of the study to be replicated, that a replication is more appropriate for MA students, and some thought that including a replication study could "limit options for getting some jobs" (respondent 204) or "harm their career" (respondent 115).

Third, when asked what percentage of empirical studies in L2 research they thought had been replicated (Q1.5), the most common response was "up to $10 \%$ " $(56.5 \%, n=200)$, followed by "up to $25 \%$ " $(22.6 \%, n=80)$ and "about $50 \%$ " $(6.5 \%, n=23)$. Survey respondents were mostly 
agreed, therefore, that the amount of replication in the field is low. Very few respondents selected "up to $75 \%$ " $(2 \%, n=7)$ or "nearly all" $(0.8 \%, n=3)$. In addition, $79.9 \%(n=283)$ of respondents thought the amount of replication in our field should increase, while $6.8 \%(n=24)$ thought it should remain the same and 1.4\% $(n=5)$ thought it should decrease (Q1.6).

Overall, these findings suggest generally positive attitudes toward conducting replication studies in our field as well as an awareness that replication studies are infrequent.

\section{What are the practices of respondents who have carried out replication studies?}

Just over half of respondents $(54.8 \%, n=194)$ had tried to replicate an empirical study that was initially carried out by themselves or somebody else ("no response" $=0.8 \%, n=3 ; \mathrm{Q} 2.2$ ). Figure 2 shows that respondents with replication experience are quite evenly distributed across career stages.

\section{Figure 2.}

Percentage of respondents with and without replication experience by career stage

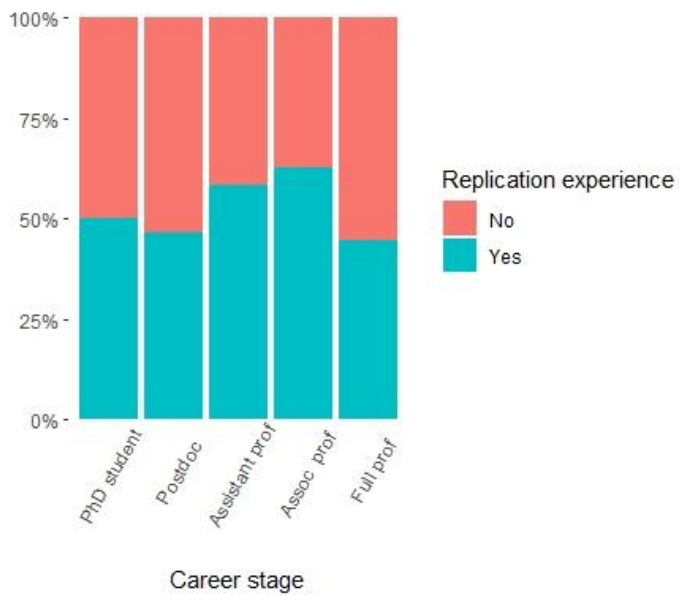


Of the 157 respondents who had never tried to replicate a study, the most common reasons for not doing so were: "I did not have a reason" $(31.8 \%, n=50$,), "I am concentrated on an original line of research with no time/interest/wish to replicate others" $(22.3 \% n=35)$, and "Replicating an empirical study is less impactful than conducting an original empirical study" $(n=29,18.5 \%$; Q2.3). In addition, 65\% (n=102) of the 157 respondents without replication experience indicated that they wanted to carry out a replication at some point in the future ("no response" $=17.2 \%, n=27 ; \mathrm{Q} 2.4)$. Also connected with replication practices is the extent to which respondents (with and without replication experience) had been contacted by someone else who wanted replicate one of their studies (Q2.1). The majority of respondents $(75.4 \%, n=267)$ had never been contacted by another researcher who wanted to replicate one of their studies $(23.4 \%$, $n=83$, of respondents were contacted by another researcher, 4 respondents selected "no response").

The 194 respondents with replication experience were asked additional questions about their practices. Just over half of this sample had replicated at least one of their own studies $(52.6 \%, n=102 ;$ "no response" $=6$; Q2.6). In terms of the types of replication studies conducted, close/partial replications were the most common: $69.1 \%(n=134)$ of respondents had carried out at least one close/partial replication study, 56.7\% $(n=110)$ had carried out at least one conceptual replication, and $21.6 \%(n=42)$ had carried out at least one exact replication study (Q2.7). In addition, respondents were asked about the conclusions of their completed replication studies (Q2.8): $56.2 \%(n=109)$ of replications reported in the sample reached the same conclusions as the initial study.

In terms of dissemination, most respondents indicated that they had presented a replication study at a conference or meeting $(74.2 \%, n=144)$. Just under one quarter of 
respondents reported that they had not presented their replication work at conferences/meetings $(23.2 \%, n=45 ;$ "no response" $=2.6 \%, n=5 ; \mathrm{Q} 2.9)$. Respondents were also asked about the publishing venues used for disseminating their replication work. Out of the 340 completed replication studies reported in the sample, $52.4 \%(n=178)$ of replications had been published in a peer-reviewed journal, with fewer replication studies published in books and book chapters $(17.6 \%, n=60)$ and in non-peer-reviewed journal articles $(6.2 \%, n=21 ;$ Q2.10). However, 23.8\% $(n=81)$ of completed replications had not been published (excluding replications under review and/or in preparation). These findings indicate that peer-reviewed journals represent the primary publishing venue of replication studies in the field. However, almost one quarter of completed replications in our field may be unpublished.

Related to publishing venues, respondents were asked whether they had encountered any difficulties publishing their replications (Q2.11). Almost half of respondents indicated no difficulties publishing the results of their replications $(49.1 \%, n=83$, excluding replications in progress, $n=25$; "no response", $n=33$ ). For respondents who did encounter difficulties publishing their replication studies, the main reasons were that the manuscript had to be submitted to several journals before it was published $(8.9 \%, n=15)$, that the manuscript had to be expanded by including a new study $(8.3 \%, n=14)$, and that the editors and/or reviewers were reluctant to publish the results $(5.9 \%, n=10)$. Lastly, respondents were asked how many of their published replication studies had been explicitly labeled as a replication in the title or abstract $(\mathrm{Q} 2.12)$. Half of respondents stated that none of their replications were explicitly labeled in the title or abstract $(50 \%, n=97)$. In terms of the raw number of published replications reported in the sample, only 111 out of 208 replication studies (or 53.4\%) were reported to include explicit 
labeling. These findings suggest that close to half of replications in our field might not be explicitly labeled as replication studies.

\section{In what ways do researcher background variables relate to attitudes toward replication?}

Finally, the extent to which respondents' attitudes toward replication (Q1.4) might be related to the background variables of years since $\mathrm{PhD}(\mathrm{Q} 3.2)$, career stage (Q3.3), publication rate (Q3.4), and number of research methods and/or statistics courses taken (Q3.5) was examined. Overall, no meaningful relationships were found among attitudes and career stage, years since $\mathrm{PhD}$, and publication rate. For research methodology courses taken, however, a small number of relationships emerged (see Table 4 and supplementary materials for scatterplots). The magnitude of these relationships was small with CIs that did not cross zero. In particular, respondents who reported having taken more research methods courses indicated more positive attitudes toward replication, both in terms of the relevance and value of replications to the field as well as a means to "strengthen a discipline". In addition, a negative relationship was found between research methods experience and the statement "replications question the original researcher and their findings". Even though the magnitude of these relationships is small and should therefore be interpreted cautiously, they appear to suggest connections between studying research methodology and positive attitudes toward replication. 


\section{Table 4.}

Spearman's Rho's correlations with 95\% confidence intervals between attitudes toward replication and background characteristics

\begin{tabular}{|c|c|c|c|c|}
\hline \multirow{3}{*}{$\begin{array}{l}\text { Replications... } \\
\text { lack originality }\end{array}$} & Career stage & Years since $\mathrm{PhD}$ & Publication rate & Research methods courses taken \\
\hline & 0.06 & 0.06 & 0.08 & 0.05 \\
\hline & $-0.05,0.18$ & $-0.05,0.17$ & $-0.04,0.20$ & $-0.06,0.18$ \\
\hline \multirow[t]{2}{*}{ generalize previous results } & 0.05 & 0.02 & 0.11 & 0.04 \\
\hline & $-0.06,0.16$ & $-0.09,0.14$ & $-0.01,0.22$ & $-0.07,0.15$ \\
\hline question the original researcher and their & 0.03 & -0.01 & -0.00 & -0.13 \\
\hline findings & $-0.09,0.14$ & $-0.13,0.10$ & $-0.12,0.12$ & $-0.25-0.02$ \\
\hline are not a priority in L2 research right now & $\begin{array}{c}-0.03 \\
-0.14 .0 .07\end{array}$ & $\begin{array}{c}-0.03 \\
-0.14 .0 .07\end{array}$ & $\begin{array}{c}-0.11 \\
-0.22 .0 .02\end{array}$ & $\begin{array}{c}0.03 \\
-0.080 .14\end{array}$ \\
\hline build academic reputations & $\begin{array}{l}-0.05 \\
-0.15,0.07\end{array}$ & $\begin{array}{c}-0.08 \\
-0.28 .0 .03\end{array}$ & $\begin{array}{c}0.02 \\
-0.11 .0 .14\end{array}$ & $\begin{array}{c}0.03 \\
-0.09 .0 .14\end{array}$ \\
\hline verify previous results & $\begin{array}{l}-0.07 \\
-0 \\
-0.03\end{array}$ & $\begin{array}{ll}-0.09 \\
-021002\end{array}$ & $\begin{array}{l}-0.03 \\
016008\end{array}$ & 0.11 \\
\hline are negatively evaluated by reviewers & $\begin{array}{l}-0.19,0.03 \\
-0.04\end{array}$ & $\begin{array}{l}-0.21,0.02 \\
-0.08\end{array}$ & $\begin{array}{l}-0.16,0.08 \\
-0.02\end{array}$ & $\begin{array}{c}-0.01,0.23 \\
0.06\end{array}$ \\
\hline expand previous results & $\begin{array}{l}-0.17,0.07 \\
-0.03\end{array}$ & $\begin{array}{l}-0.20,0.03 \\
-0.11\end{array}$ & $\begin{array}{l}-0.13,0.11 \\
-0.09\end{array}$ & $\begin{array}{c}-0.06,0.18 \\
0.04\end{array}$ \\
\hline establish knowledge & $\begin{array}{l}-0.14,0.08 \\
-0.04\end{array}$ & $\begin{array}{l}-0.22,0.02 \\
-0.00\end{array}$ & $\begin{array}{l}-0.21,0.03 \\
0.02\end{array}$ & $\begin{array}{l}-0.07,0.16 \\
0.06\end{array}$ \\
\hline & $-0.16,0.06$ & $-0.11,0.11$ & $-0.09,0.15$ & $-0.05,0.18$ \\
\hline are used to learn about research methods & $\begin{array}{c}-0.08 \\
-0.19,0.04\end{array}$ & $\begin{array}{c}-0.12 \\
-0.23,0.00\end{array}$ & $\begin{array}{c}-0.10 \\
-0.22,0.02\end{array}$ & $\begin{array}{c}-0.02 \\
-0.14,0.09\end{array}$ \\
\hline are relevant to $\mathrm{L} 2$ research & $\begin{array}{c}-0.02 \\
-0.13,0.09\end{array}$ & $\begin{array}{c}-0.06 \\
-0.17,0.07\end{array}$ & $\begin{array}{c}0.03 \\
-0.09,0.15\end{array}$ & $\begin{array}{c}0.16 \\
0.04,0.28\end{array}$ \\
\hline strengthen a discipline & $\begin{array}{c}-0.04 \\
-0.15,0.07\end{array}$ & $\begin{array}{c}-0.07 \\
-0.18,0.04\end{array}$ & $\begin{array}{c}0.10 \\
-0.02,0.21\end{array}$ & $\begin{array}{c}0.17 \\
0.05,0.27\end{array}$ \\
\hline consolidate previous results & $\begin{array}{c}0.01 \\
-0.11,0.12\end{array}$ & $\begin{array}{c}-0.01 \\
-0.13,0.10\end{array}$ & $\begin{array}{c}0.10 \\
-0.01,0.22\end{array}$ & $\begin{array}{c}0.10 \\
-0.00,0.21\end{array}$ \\
\hline are valuable to the field & $\begin{array}{c}-0.05 \\
-0.16,0.07\end{array}$ & $\begin{array}{c}-0.08 \\
-0.19,0.03\end{array}$ & $\begin{array}{c}0.08 \\
-0.04,0.20\end{array}$ & $\begin{array}{c}0.15 \\
0.04,0.26\end{array}$ \\
\hline lack innovation & $\begin{array}{c}0.09 \\
-0.03,0.20\end{array}$ & $\begin{array}{c}0.12 \\
-0.00,0.24\end{array}$ & $\begin{array}{c}0.08 \\
-0.04,0.20\end{array}$ & $\begin{array}{c}0.04 \\
-0.08,0.16\end{array}$ \\
\hline
\end{tabular}

Note. Grey highlighting indicates correlations with CIs that do not cross zero 


\section{Discussion}

The current study aimed to better understand why replication studies appear to be infrequent in L2 research by surveying 354 researchers about their attitudes toward replication and their practices conducting replication studies. Overall, respondents evaluated replication studies as valuable and relevant to the field and thought that replications can strengthen a discipline and consolidate previous results. In addition, respondents tended to disagree with claims that replication studies lack originality or innovation. Furthermore, most respondents would recommend others to carry out replication studies, would support $\mathrm{PhD}$ students to carry out replications, and considered that the amount of replication in the field should increase. Altogether, these findings suggest that researchers in L2 studies judge replications to be valuable and relevant to the discipline.

In terms of the practices of researchers who have conducted replications in L2 studies, close replications were reported to be the most common and more than half of replications reached the same conclusions as the initial study. In terms of dissemination, four trends emerged. First, approximately one quarter of respondents had not presented their replication work at conferences/meetings. Second, one third of respondents had not published their completed replications (excluding replications under review or in preparation). Third, approximately half of completed replication studies were published in peer-reviewed journals. Forth, only half of replication studies in the sample were reported to be explicitly labeled as a replication in the title or abstract. This last finding indicates that almost half of published replication studies in the field might not be identified as replications.

Lastly, few relationships were found among attitudes toward replication and the background characteristics of career stage, years since $\mathrm{PhD}$, and publication rate. However, a 
small number of associations with research methods training were evident, potentially suggesting that experience studying and reflecting on research methodology could impact attitudes toward replication research in our field.

Taken together, these findings suggest positive attitudes towards replication in L2 research and room for improvement in the reporting and dissemination of replication studies. However, it is important to note that the inevitable effects of self-selection on the current study's conclusions cannot be ruled out (see Dörnyei \& Taguchi, 2010), even though attempts were made to obtain a broad and large sample of the target population, including respondents with and without replication experience and from different career stages around the world. This is because all respondents were volunteers. It is therefore important for future research to replicate this study. In addition, replications in other disciplines and at different points in time (e.g., five-to-ten years from now) are needed to document potential variations across disciplines and changing attitudes and practices. Integrating qualitative data from follow-up interviews or focus groups into future replications could also offer a more comprehensive account of replications practices and attitudes in the field.

\section{Improving the discoverability of replication studies}

Returning to this study's general aim to better understand why replications appear to be infrequent in L2 research, the findings indicate that negative attitudes are probably not the sole explanation. Reporting and dissemination practices have likely played an important role in reducing the discoverability of replication studies and limiting their potential impact on the field.

One simple way to address this issue and improve the discoverability of replication studies is to use explicit labeling in the title and abstract (see Appelbaum et al., 2018; Porte \& 
McManus, 2019). As previously noted, what might be perceived as a lack of replication could be a lack of transparent labeling. For example, in Marsden et al.'s (2018) review of self-labeled replication studies in L2 research, only 13 of the 63 published articles (or 21\%) included the label 'replication' in the title. In contrast, a recent meta-analysis of meta-analyses in English language teaching showed that 84 of the 90 meta-analyses (or 93\%) included the label 'metaanalysis' or 'research synthesis' in the title (see Alsowat, 2020). By not using the label 'replication' in the study title, the discoverability of replications and their potential impact on the field are being limited. Explicit labeling of replication research in the title and abstract can improve the discoverability of replication research.

Providing targeted support and training to researchers in planning and reporting their replication studies is another way that can address reporting and dissemination issues (see also Marsden et al., 2018). Compared with other types of research like meta-analysis and "original" research, for example, very little guidance exists to support researchers in the design, conduct, and reporting of replications (but see Porte \& McManus, 2019). Because replications appear to be infrequent, researchers likely require additional support to design and report replication studies. As a result, researchers may lack awareness about (i) how replication and "original" research studies differ in function, structure, and presentation as well as (ii) how to convey the unique value of replication studies to editors, reviewers, and readers (see Appelbaum et al., 2018; Porte \& McManus, 2019). Therefore, an additional explanation for the infrequency of replication studies in our field could be that researchers lack exposure and necessary experience and training in research methodology and dissemination to effectively design and report replication studies. The field can address this potential challenge by creating discipline-specific resources for planning and conducting replication studies. 
Based on the current study's findings, five recommendations are proposed to facilitate and improve the discoverability, amount, and quality of replication in L2 studies:

1. Replication studies should include the label 'replication' in the study title and abstract.

2. Systematic research training should be provided during conferences at no additional cost to attendees about how to design, present, and write-up (replication) research studies.

3. Field-specific resources and reporting guidelines should be developed that include recommendations for designing, presenting, and disseminating replication studies, including interpretation guidelines (e.g., Norris et al., 2015).

4. Journals should tag replications on their websites and link them to the initial study.

5. Authors should systematically discuss approaches to replication, with rationales, in published research studies.

By improving the discoverability of replications through transparent labeling, tagging, and linking as well as investing in the research methodology and dissemination training of researchers, we can at least begin to address concerns about the frequency and quality of replication studies in our field.

\section{Conclusions}

The current study's findings show that researchers in L2 studies attach considerable relevance and value to replication. As a result, additional explanations for the infrequency of replication studies in our field are needed. Results concerning dissemination practices indicate systemic reporting limitations that are likely reducing the discoverability and impact of 
replication studies. Based on the current study's findings, recommendations are proposed to address reporting and dissemination issues in the field, including explicit labeling of replication studies in the title and abstract, the development of field-specific resources and standards for reporting and interpreting replication studies, and systematic training in how to plan, present, and disseminate replication studies.

\section{References}

Ahadi, A., Hellas, A., Ihantola, P., Korhonen, A., \& Petersen, A. (2016). Replication in computing education research: Researcher attitudes and experiences. Proceedings of the 16th Koli Calling International Conference on Computing Education Research, 2-11. https://doi.org/10.1145/2999541.2999554

Alsowat, H. H. (2020). Evidence-based practices of English language teaching: A meta-analysis of meta-analyses. English Language Teaching, 13(11), 75. https://doi.org/10.5539/elt.v13n11p75

Appelbaum, M., Cooper, H., Kline, R. B., Mayo-Wilson, E., Nezu, A. M., \& Rao, S. M. (2018). Journal article reporting standards for quantitative research in psychology: The APA Publications and Communications Board task force report. American Psychologist, 73(1), 3-25. https://doi.org/10.1037/amp0000191

Byrnes, H. (2013). Notes from the Editor. The Modern Language Journal, 97(4), 825-827. https://doi.org/10.1111/j.1540-4781.2013.12051.x

Cumming, G., \& Calin-Jageman, R. (2017). Introduction to the new statistics: Estimation, open science, and beyond. Routledge. 
Dörnyei, Z., \& Taguchi, T. (2010). Questionnaires in second language research: Construction, administration, and processing (2nd ed). Routledge.

Easley, R. W., Madden, C. S., \& Gray, V. (2013). A tale of two cultures: Revisiting journal editors' views of replication research. Journal of Business Research, 66(9), 1457-1459. https://doi.org/10.1016/j.jbusres.2012.05.013

Gass, S. M., Loewen, S., \& Plonsky, L. (2021). Coming of age: The past, present, and future of quantitative SLA research. Language Teaching, 54(2), 245-258. https://doi.org/10.1017/S0261444819000430

Gass, S. M., \& Plonsky, L. (2020). Introducing the SSLA Methods Forum. Studies in Second Language Acquisition, 42(4), 667-669. https://doi.org/10.1017/S0272263120000364

Hervé, M. (2021). RVAideMemoire: Testing and plotting procedures for biostatistics (0.9-79) [Computer software]. https://CRAN.R-project.org/package=RVAideMemoire Isbell, D. R., Brown, D., Chan, M., Derrick, D., Ghanem, R., Gutiérrez Arvizu, M. N., Schnur, E., Zhang, M., \& Plonsky, L. (under review). Misconduct and questionable research practices: The ethics of quantitative data handling and reporting in applied linguistics. Manuscript under Review.

Language Teaching Review Panel. (2008). Replication studies in language learning and teaching: Questions and answers. Language Teaching, 41(1), 1-14. https://doi.org/10.1017/S0261444807004727

Loewen, S., Gönülal, T., Isbell, D. R., Ballard, L., Crowther, D., Lim, J., Maloney, J., \& Tigchelaar, M. (2020). How knowledgeable are Applied Linguistics and SLA researchers about basic statistics?: Data from North America and Europe. Studies in Second Language Acquisition, 42(4), 871-890. https://doi.org/10.1017/S0272263119000548 
Marsden, E., Morgan-Short, K., Thompson, S., \& Abugaber, D. (2018). Replication in second language research: Narrative and systematic reviews and recommendations for the field. Language Learning, 68(2), 321-391. https://doi.org/10.1111/lang.12286

Mu, C., \& Matsuda, P. K. (2016). Replication in L2 writing wesearch: Journal of Second Language Writing authors' perceptions. TESOL Quarterly, 50(1), 201-219. https://doi.org/10.1002/tesq.284

Norris, J. M., Plonsky, L., Ross, S. J., \& Schoonen, R. (2015). Guidelines for reporting quantitative methods and results in primary research: Guidelines for reporting quantitative methods. Language Learning, 65(2), 470-476. https://doi.org/10.1111/lang.12104

Olalla-Soler, C. (2020). Practices and attitudes toward replication in empirical translation and interpreting studies. Target: International Journal on Translation Studies, 32(1), 3-36. https://doi.org/10.1075/target.18159.ola

Plonsky, L. (2013). Study quality in SLA: An assessment of designs, analyses, and reporting practices in quantitative L2 research. Studies in Second Language Acquisition, 35(4), 655-687. https://doi.org/10.1017/S0272263113000399

Plonsky, L., \& Oswald, F. L. (2014). How big Is “Big”? Interpreting effect sizes in L2 research. Language Learning, 64(4), 878-912. https://doi.org/10.1111/lang.12079

Porte, G. K. (Ed.). (2012). Replication research in applied linguistics. Cambridge University Press.

Porte, G. K., \& McManus, K. (2019). Doing replication research in applied linguistics. Routledge. 
Porte, G. K., \& Richards, K. (2012). Replication in second language writing research. Journal of Second Language Writing, 21(3), 284-293. https://doi.org/10.1016/j.jslw.2012.05.002

Qualtrics. (2021). Qualtrics (July 2021) [Computer software]. https://www.qualtrics.com

R Core Team. (2021). $R$ : A language and environment for statistical computing (1.4.1717)

[Computer software]. R Foundation for Statistical Computing. https://www.Rproject.org/

Schmidt, S. (2009). Shall we really do it again? The powerful concept of replication is neglected in the social sciences. Review of General Psychology, 13(2), 90-100. https://doi.org/10.1037/a0015108

VanPatten, B., Keating, G. D., \& Wulff, S. (Eds.). (2020). Theories in second language acquisition: An introduction (Third edition). Routledge.

Zwaan, R. A., Etz, A., Lucas, R. E., \& Donnellan, M. B. (2018). Making replication mainstream. Behavioral and Brain Sciences, 41, e120. https://doi.org/10.1017/S0140525X17001972

\section{Acknowledgements}

I am very grateful to all survey respondents for their time and contributions to this study, to members of SLA reading group at Penn State, and to Yingying Liu and Amanda Huensch. I would also like to thank SSLA editor Susan Gass and the valuable feedback from four reviewers. 